\title{
Simple demonstration of the electrical residue
}

\section{Fr. Stenger}

To cite this article: Fr. Stenger (1886) Simple demonstration of the electrical residue, Philosophical Magazine Series 5, 22:134, 80-80, DOI: 10.1080/14786448608627903

To link to this article: http://dx.doi.org/10.1080/14786448608627903

曲 Published online: 29 Apr 2009.

Submit your article to this journal 준

Џll Article views: 2

Q View related articles $₫$ 
In a second copy of the same instrument, which I have the honour to place before the Academy, the system of two hemispheres is contained within a concentric spherical envelope, which is connected with the earth. This arrangement increases the sensitiveness of the instrument, and protects it from air-currents as well as from extraneous electrical influences.

If $a$ and $b$ are the radii of the two concentric spheres, we have the formula

$$
p=\frac{1}{8} \frac{b^{2}}{(b-a)^{2}} \nabla^{2}
$$

In this case we have $a=3.9$ centims., $b=4.92, p=3.322$ grams. Hence if we place a millimetre scale at 1 metre from the rule, we have for the value of the deflection,

$$
d=0 \cdot 00373 \mathrm{~V}^{2} \text {. }
$$

If $\mathrm{V}$ is expressed in volts, we have

$$
d=0.0000140 \mathrm{~V}^{3} \text {. }
$$

It is desirable to multiply optically the sensitiveness of the instrument by reading the deflections with an ocnlar which magnities 15 to 50 times. This also diminishes in the same ratio the small deformation which the system of the spheres undergoes owing to the deflection.-Comptes Rendus, March 22, 1886.

\section{SIMPLE DEMONSTRATION OF THE ELECTRICAL RESIDUE.} BY FR. STENGER.

If two strips of tintoil are fastened at a suitable distance on a glass tube which has been evacuated as completely as possible, and are connected with the electrodes of an induction-coil, continuous electrical currents are formed in the interior, and the gas becomes intensely luminous. If, then, the two tinfoil rings are insulated, the tube becomes luminous at frequent intervals, and frequently for several minutes together. This doubtless arises from the formation of a residue on the sides of the glass. The experiment was made in a far more striking manner as follows:- In a glass tube, about 2 centim. in the clear, closed at one end, a thin metal foil was introduced so that it covered about half the inner side. A wire soldered to this plate was hermetically sealed in the tube, and was provided on the outside with a small knob. Opposite the metal cylinder a strip of tinfoil was fastened. This small Leyden jar was then rarefied as completely as possible, and hermetically sealed. If this was charged from a small electrical machine for ten or fifteen minutes the residual electricities could be discharged, producing a bright illumination in the tube. This method of rendering visible very small quantities of electricity might possibly be used in repeating in another form the experiments of Rowland and Nichols*, on the formation of the residue in quartz and calc-spar, which are of theoretical interest.-Wiedemann's Amalen, No. 6, 1886.

* Rowland and Nichols, Phil. Mag. [5] xi. p. 414 (1881). 